\title{
Rh-Promoted Carbon Catalysts to Obtain Clean Components of Motor Fuels
}

\author{
S. K. Tanyrbergenova, A. Temirkhan, Z. A. Mansurov, N. K. Zhylybayeva, and G. M. Naurzbayeva
}

\begin{abstract}
In this work were selected the optimal conditions of the dearomatization reaction based on the hydrogenation of benzene to cyclohexane over $R h$ catalyst, which increases the octane number. The results showed that the study of the catalytic activity of $1 \% \mathrm{Rh}$ catalysts were active and selective. Carbonized apricot pits $0.5 \%$ Rh-promoted exhibits catalytic activity in hydrogenation of benzene in the temperature mode, but by increasing the space velocity rapidly loses activity. $R h$ catalyst on calcined $\mathrm{Al}_{2} \mathrm{O}_{3}$ at $550{ }^{\circ} \mathrm{C}$ showed markedly less stability in comparison to the other samples. $0.5 \% \mathrm{Rh}$ - promoted clay-containing zeolite exhibits catalytic activity in the hydrogenation of benzene in the temperature range $280-350{ }^{\circ} \mathrm{C}$, and also has high selectivity to yield of cyclohexane and DMB. As a result, turned improve the environmental performance of motor fuel to achieve the parameters corresponding to Euro-4 standards.
\end{abstract}

Index Terms-Benzene, carbon catalysts, hydrogenation, rhodium.

\section{INTRODUCTION}

The present level of quality requirements for motor fuels is determined not only by the need to ensure their performance, but also the prerequisite for environmental safety of vehicle engines. In particular, European standards tightened requirements to the contents of alkenes and aromatic hydrocarbons and sulfur in commercial diesel fuel and gasoline.

The problem of ecological fuel acquired independent significance in connection with the tightening requirements for ecological safety of diesel fuel, in particular to the content of diesel fuel with low arenas content. Technical Regulations of the Customs Union (Russia, Belarus and Kazakhstan), set requirements for different types of fuels in these countries. From 1 January 2013 all diesel fuel into circulation in the territory of the Customs Union, the indicators must be no lower than for Class 3 (analogous to Euro-3). Contain no more than $350 \mathrm{ppm}$ of sulfur and less than $11 \mathrm{wt} \%$ of polycyclic aromatic compounds, and have a cetane number of not less than 51 (for summer grades) [1].

To obtain high-octane gasoline with a low content of

Manuscript received January 28, 2015; revised April 20, 2015. This work was supported in part by the Science Committee of the Ministry of Education and Science of the Republic of Kazakhstan under Grant 1777/GF3-14-OT

S. K. Tanirbergenova and Z. A. Mansurov are with the Institute of Combustion Problems, Bogenbay batyra street, 172, Almaty, 050012 Kazakhstan (e-mail: sandu2201@mail.ru, zmansurov@kaznu.kz).

A. Temirkhan, N. K. Zhylybayeva, and G. M. Naurzbayeva are with Laboratory of Carbon Nanomaterial'S in The Institute of Combustion Problems, Bogenbay batyra street, 172, Almaty, 050012 Kazakhstan (e-mail aliya_temirkhan@mail.ru,nurzhamaljk@mail.ru,gumiw@mail.ru). aromatic hydrocarbons in their composition traditionally use alkylation and hydroisomerization processes, also oligoizomerization processes [2]. The structure of high-octane gasoline input gasoline fraction of catalytic cracking products, as well as isobutane alkylation products and hydroisomerization of $\mathrm{C}_{5}-\mathrm{C}_{6}$ alkanes [3]. All of these technologies make it possible to obtain not cause environmental problems saturated hydrocarbons - alkanes and cycloalkanes, which, although not fully, but significantly reduced the proportion of arenes in gasoline [4].

In order to the oil fraction can be used as a diesel fuel component, fraction must meet certain requirements: for it also imposes limits on the content of sulfur and aromatic compounds [5]. This limitation is due to the fact that the above fraction in the final product contains a certain amount, and at a deviation from the requirements of compounding will not yield commercial product that complies with the regulations [6].

In this work were selected the optimal conditions of the dearomatization reaction based on the hydrogenation of benzene to cyclohexane over Rh catalyst, which increases the octane number. $\mathrm{Rh}$ catalysts operate under milder conditions and have greater selectivity for compounds with a terminal double bond than conventional systems based on Co.

The aim of this work was development $\mathrm{Rh}$ catalyst for hydrogenation of benzene and studies the effect of the phase composition of the active phase to their catalytic properties in the study process.

\section{EXPERIMENTAL}

As a basis for growth and formation of nano-carbon composites used apricot pits and clay from Tonkerisskaya field (Kazakhstan).

Selection of this clay due to the fact that the composition of this clay were detected oxides $\mathrm{Fe}_{3} \mathrm{O}_{4}, \mathrm{TiO}_{2}, \mathrm{MgO}, \mathrm{Cr}_{2} \mathrm{O}_{3}$, which must promote the formation in carbonization carbon fiber and nanostructure. This causes an increase in the catalytic carbon surface area and porosity, resulting in the formation of transport pores.

Rh catalysts based on apricot seed were prepared as follows: AS-impregnated with salts of metals was reduced at $500{ }^{\circ} \mathrm{C}$ in an atmosphere of hydrogen. Carbonized apricot pits as solid carbon matrix is a durable material which has a porous structure. Prepared samples were loaded into the hydrocracking reactor and tested in hydrocracking, hydroisomerization and hydrogenation of hydrocarbons processes.

$\mathrm{Rh}$ catalysts based on zeolite were prepared by impregnation followed by calcinations. The impregnation was 
performed by immersing the matrix in a concentrated solution of a rhodium salt. The impregnated zeolite was subjected to carbonization process for 3-5 hours. The obtained catalyst containing $0.5-1 \%$ of rhodium using for hydrogenation.

Investigation of carbonized materials structure using SEM (Microscope Quanta 3D 200i CEI, made in USA, with an accelerating voltage of $30 \mathrm{kV}$ ) have shown that the obtained samples have a structure with varying wall thickness and pore size, as a result of which appear to be drastically reduced the activation energy of different chemisorptions reactions. When this does not change the morphology of the material and the surface structure is dense.

Investigation of activity of synthesized catalysts were performed in the high-pressure laboratory flow in the temperature range $50-300{ }^{\circ} \mathrm{C}$, pressure $0.1-3.0 \mathrm{MPa}$, and a volume rate of 1.0-4.0 h-1. The hydrogen feed rate was 30-60 $\mathrm{ml} / \mathrm{min}$.

Electron microscopic study of the samples was carried out on the JEM-100SKH device at an accelerating voltage of 100 $\mathrm{kV}$. The device allows us to study objects at high resolution (3.0 ̊).

Determination of the composition of the gas phase was carried out by gas chromatography on a Chromatograph type 3700, Chrome- 5. Content was determined in the pyrolysis products of carbon monoxide, oxygen, hydrogen and hydrocarbons.

Carbohydrate moiety analyzed on chromatography. Detector - flame ionization. Carrier gas - nitrogen, stainless steel column of $3 \mathrm{~m}$ length and $3 \mathrm{~mm}$ in diameter, the sorbent $\gamma-\mathrm{A}_{2} \mathrm{O}_{3}$ temperature from 90 to $180{ }^{\circ} \mathrm{C}$.

\section{RESULTS AND DISCUSSION}

The work investigated the hydroisomerization reaction of benzene comprising a stage of hydrogenation to cyclohexane $(\mathrm{CH})$, followed by isomerization to methylcyclopentane (MCP) on Rh-promoted carbon catalyst. As a matrix used a pure zeolite and its mixture with clay, $\gamma-\mathrm{Al} 2 \mathrm{O} 3$, with their ratio was varied within wide limits. Rhodium deposited by impregnation of solutions of rhodium nitrate salts.

A different concentration of rhodium was applied to a series of matrix: $\mathrm{Al}_{2} \mathrm{O}_{3}$, zeolite, clay, carbonized apricot pits. We also produced Co- promoted catalysts for comparison of catalytic activity.

The physical and chemical characteristics of the produced catalysts (see Table I). To create the carbon catalyst for hydrogenation deposited rhodium salts on matrix. Supported rhodium metal centers allow equilibrium to maintain a low concentration of olefins in the reaction mixture and prevent coking of the catalyst surface. Carbonization of zeolite samples lasted 5 hours, with the purpose of increasing the carbon content.

Among of all the tasted samples, Rh- promoted catalyst on a zeolite characterized by highest activity. It is considered that for the efficient operation of bifunctional metal catalysts metal centers should be as close as possible to the acid sites. So often a metal component is applied directly to the surface of the zeolite. Nevertheless, the catalyst containing $10 \%$ clay and zeolite promoted by $\mathrm{Rh}$ demonstrated high activity and selectivity in the hydrogenation of benzene.

TABLE I: BASIC PHYSICAL AND CHEMICAL CHARACTERISTICS OF RH-PROMOTED CARBON CATALYST ON DIFFERENT MATRIX

\begin{tabular}{ccccccc}
\hline \hline Indicators & Zeolite & Zeolite & Clay & CAP & $\begin{array}{c}\text { Zeolite }+ \\
\text { Clay }\end{array}$ & $\mathrm{Al}_{2} \mathrm{O}_{3}$ \\
\hline $\begin{array}{c}\text { Rhodium } \\
\text { content }(\% \text { wt.) }\end{array}$ & - & 0.5 & 0.5 & 0.5 & 0.5 & 0.5 \\
$\begin{array}{c}\text { Carbon content } \\
\quad \% \text { wt.) }\end{array}$ & - & 5.0 & 15.0 & 21.0 & 12.0 & 9.0 \\
$\begin{array}{c}\text { Specific } \\
\text { surface }\left(\mathrm{m}^{2} / \mathrm{g}\right) \\
\begin{array}{c}\text { Carbonization } \\
\text { (hour) }\end{array}\end{array}$ & 112.0 & 122.0 & 106.0 & 452.0 & 156.0 & 96.0 \\
\hline \hline
\end{tabular}

It was established experimentally that $0.5 \%$ Rh-promoted carbonized apricot pits (CAP) are catalytically active in the hydrogenation of benzene. According to the chromatographic analysis data the optimal temperature of $430{ }^{\circ} \mathrm{C}$ and pressures of $20 \mathrm{~atm}$. for the benzene hydrogenation, benzene conversion is $64 \%$ (Table II). In hydrogenation of benzene reaction over rhodium catalysts hydrogen feed rate $60 \mathrm{ml} / \mathrm{min}$ and feed rate of benzene with $0.1 \mathrm{ml} / \mathrm{min}$. By increasing the hydrogen feed over rhodium catalyst at temperatures above $480{ }^{\circ} \mathrm{C}$ in the reaction products is found small amounts of hexane. Under given conditions, the isomerization of cyclohexane to methylcyclopentane not observed.

Results of the hydrogenation of benzene over cobalt and rhodium carbon catalyst at a temperature of $450{ }^{\circ} \mathrm{C}$ and 25 atm. (see Table II) Composition benzene hydrogenation products depends not only on the activity of the catalyst, and the conditions of supply of hydrogen and benzene. From the experimental results that with the increase in the initial feed mixture of benzene, cyclohexane yield gradually decreases due to the lack of hydrogen. Over Co- promoted catalysts benzene conversion $51 \%$ at a temperature of $430{ }^{\circ} \mathrm{C}$.

TABLE II: BENZENE CONVERSION AT VARIOUS CATALYSTS (CAP)

\begin{tabular}{cccc}
\hline \hline $\mathrm{T},{ }^{0} \mathrm{C}$ & \multicolumn{3}{c}{ Benzene conversion, \% } \\
350 & 47 & $5 \% \mathrm{Co}$ & $7 \% \mathrm{Co}$ \\
\hline 380 & 49 & 24 & 27 \\
400 & 59 & 29 & 32 \\
430 & 64 & 33 & 35 \\
450 & 65 & 41 & 42 \\
480 & 65 & 42 & 45 \\
\hline \hline
\end{tabular}

Identified the optimal conditions for the benzene hydrogenation over $\mathrm{Rh}$ catalyst. The maximum yield of cyclohexane over Rh-promoted catalyst at a temperature of $430{ }^{\circ} \mathrm{C}$, over Co-promoted catalyst the maximum yield of cyclohexane at a temperature of $480{ }^{\circ} \mathrm{C}$ and a pressure of 20 atm. Aromatics feed of $10 \mathrm{ml} / \mathrm{min}$, and the hydrogen $60 \mathrm{ml}$ /min.

Widely studied changing of the hydrogen: benzene molar ratio. Increasing hydrogen partial pressure reduces the coking rate of $\mathrm{Rh}$-promoted zeolite catalysts.

Impact of hydrogen: benzene ratio to the result in the 
benzene hydrogenation processes (see Table III). Increase the ratio of hydrogen above 8: 1 is impractical because the reaction products, a large number of hexane.

Investigation of the catalytic activity of the synthesized series Rh-promoted catalysts on different matrix in the hydrogenation reaction of benzene showed that yield of cyclohexane and targeted products is optimal catalyst supported on synthetic zeolite composition $1 \% \mathrm{Rh}$.

The catalytic activity of the product yield in the conversion of benzene to cyclohexane carriers arranged in a row: zeolite $>$ zeolite + clay $\geq$ clay $>\mathrm{Al}_{2} \mathrm{O}_{3}>\mathrm{CAP}$.

TABLE III: IMPACT OF HYDROGEN: BENZENE RATIO

\begin{tabular}{ccccc}
\hline \hline \multirow{2}{*}{ Indicators } & $3: 1$ & \multicolumn{4}{c}{ Ratio hydrogen: benzene } \\
& & $4: 1$ & $6: 1$ & $8: 1$ \\
\hline Benzene conversion & 32 & 68 & 74 & 81 \\
Yield 2.2 DMB & 5 & 10.2 & 14.9 & 11.2 \\
Yield cyclohexane & 20 & 40 & 49 & 39 \\
\hline \hline
\end{tabular}

At the initial zeolite hydrogenation of benzene is very low. Over $1 \% \mathrm{Rh}$ zeolite reaction begins at a temperature of $250{ }^{\circ} \mathrm{C}$ and at $380{ }^{\circ} \mathrm{C}$ and higher temperature formed benzene isomers. To by-products are isomeric hydrocarbons methylcyclohexane, ethylcyclohexane and small quantities of hydrogen. With increasing temperature of the process increasing benzene conversion and selectivity of isomers of aromatic hydrocarbons. By increasing the space velocity decreases the conversion and selectivity of the target products Thus, over $1 \%$ Rh zeolite main direction of the process when hydrogenating benzene to cyclohexane followed by subsequent isomerization reactions in such cases would require additional amounts of hydrogen.

As is known, isoparaffinic hydrocarbons in gasoline octane number average determined within $72-76$ points, and aromatic hydrocarbons have octane in the range 96-120 points, and characterized by a significant increase in refractive index and reduced aniline point gasoline. Thus, we must determine the favorable conditions for the hydrogenation of aromatic hydrocarbons, which increase the octane number.

In order to elucidate the nature of the catalytic activity, as well as factors affecting the stability was investigated the influence of the environment on the reaction of benzene hydrogenation. Fig. 1 shows relationship between temperature and benzene conversion over $\mathrm{Rh}$ catalysts of hydrogenation over $0.5 \% \mathrm{Rh}$ catalyst at a pressure of $18 \mathrm{~atm}$. conversion of benzene depending on temperature.

In case the catalyst system is recovered in a hydrogen atmosphere, the benzene hydrogenation proceeds with a high yield and can reduce the temperature to $300{ }^{\circ} \mathrm{C}$. It can be seen that the maximum activity observed for the composition, wherein the rhodium is present in an amount of $1 \%$ on the carbon support (CAP).

Thus, it is shown that the regeneration of the catalysts in a hydrogen atmosphere restores the activity of the studied catalysts in benzene hydrocracking.

Fig. 2 shows the results of the study relationship between benzene conversion and time under the pressure of $30 \mathrm{~atm}$. and temperature at $400{ }^{\circ} \mathrm{C}$. The experimental data shows that the Rh-promoted zeolite catalyst (carburized 3 hours) loses the catalytic activity, worked 22 hours. A Rh- promoted CAP worked under the same conditions of 26 hours.

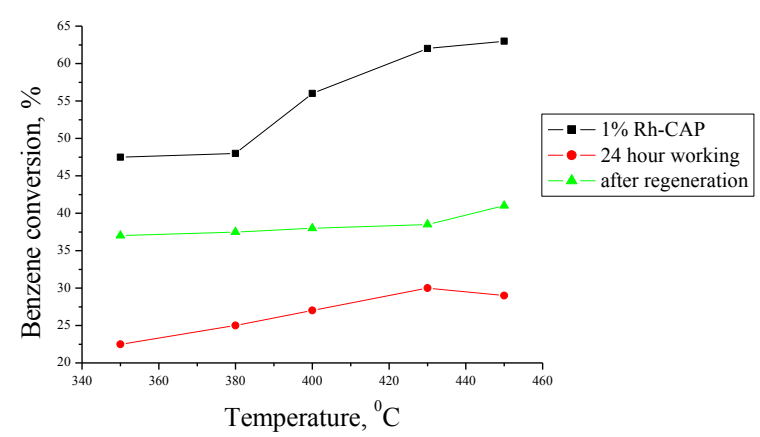

Fig. 1. Relationship between temperature and benzene conversion over Rh catalysts.

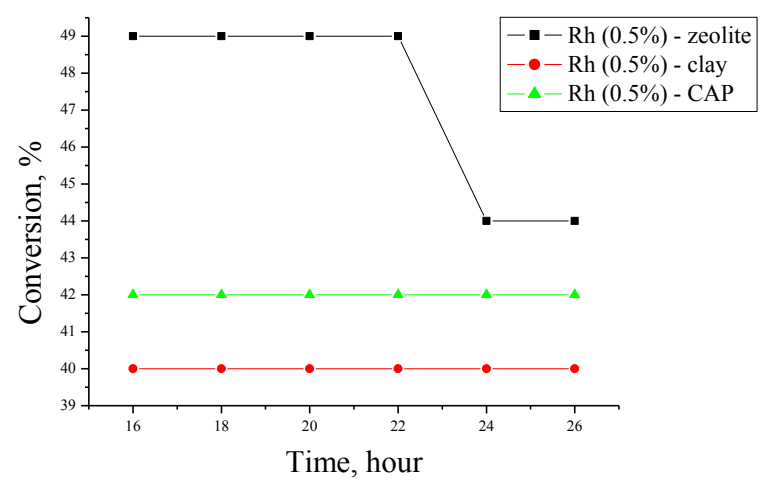

Fig. 2. Relationship between benzene conversion and time under the pressure of $30 \mathrm{~atm}$.

Investigation of valuable by-products of benzene hydrogenation over $\mathrm{Rh}$ catalyst was developed for the installation of running at pressures of 18 -25 atm. and temperatures 250 - $320{ }^{\circ} \mathrm{C}$. As catalysts, Rh- promoted catalysts are used on carbon (CAP), zeolite and a zeolite with the addition of clay.

Catalysts activity in the benzene hydrogenation reactions determined by two parameters - the proportion of 2, 2 dimethylbutane $(2,2-\mathrm{DMB})$ in the mixture of isomers and the proportion of methylcyclopentane in its mixture with cyclohexane. This indicator characterizes catalyst activity in the isomerization reaction of cyclohexane to methylcyclopentane. Fig. 3 shows the yield of 2, 2 - DMB over different catalysts depending on the temperature. As seen in Fig. 3 yield of 2, 2 DMB over $0.5 \%$ Rh zeolite was $12.4 \%$, and high yield on catalyst zeolite + clay $+1 \%$ rhodium $-17 \%$.

Based on the experimental data, we assume that the structural characteristic, the particle size distribution and bulk density of the clay as a dispersant have some influence on the catalyst productivity.

Clay-containing zeolite catalyst with a lower surface area has better stability. According to the mechanism of benzene hydrogenation small surface area prevents complete benzene hydrogenation. And inhibits further hydrogenation of cyclohexene into cyclohexane, and thus increases the selectivity of a cyclohexene. Homogeneous chemical 
environment for the selective hydrogenation of benzene, as provided with a smaller particle size and narrow particle size distribution enhance stability of cyclohexene selectivity and catalyst stability. Large pore diameters useful for desorption and increases cyclohexene selectivity.

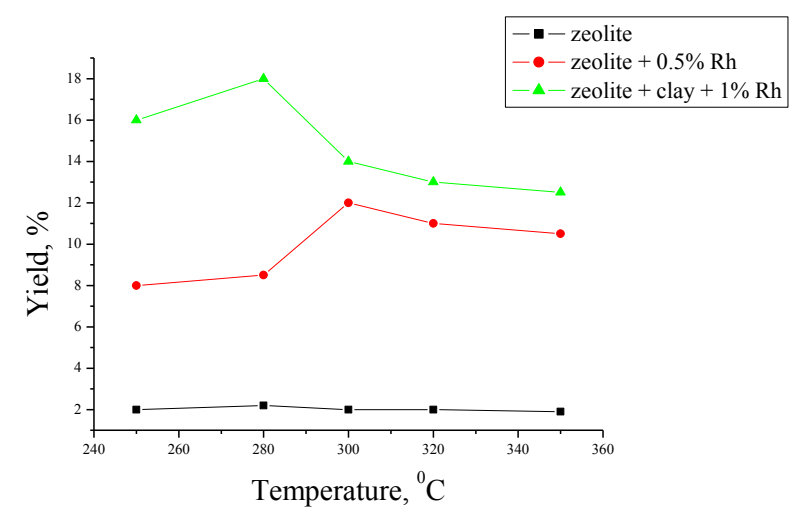

Fig. 3. Yield of 2,2-DMB over different catalysts depending on the temperatures.

Fig. 4 shows relationship between benzene conversion and pressure at $280{ }^{\circ} \mathrm{C}$ over $0.5 \% \mathrm{Rh}$ catalyst based on different matrix. As seen from the experimental data benzene conversion is $60 \%$ under 30 atm. pressure over zeolite catalyst, clay-containing zeolite to $65 \%$ under 35 atm. pressures.

Important role in the synthesis of zeolite playing structure-forming additive, as are most commonly used toxic and explosive compounds, which creates certain difficulties in the industrial production of catalysts. In this regard, great importance is the development of methods for the synthesis of high- silica zeolite using inexpensive and non-toxic compounds as structure-forming. We have synthesized $\mathrm{Rh}$ zeolite using clay as a structure-forming compound.

For use of zeolite catalysts in industrial installations necessary to increase its mechanical strength by introducing into the zeolite binder.

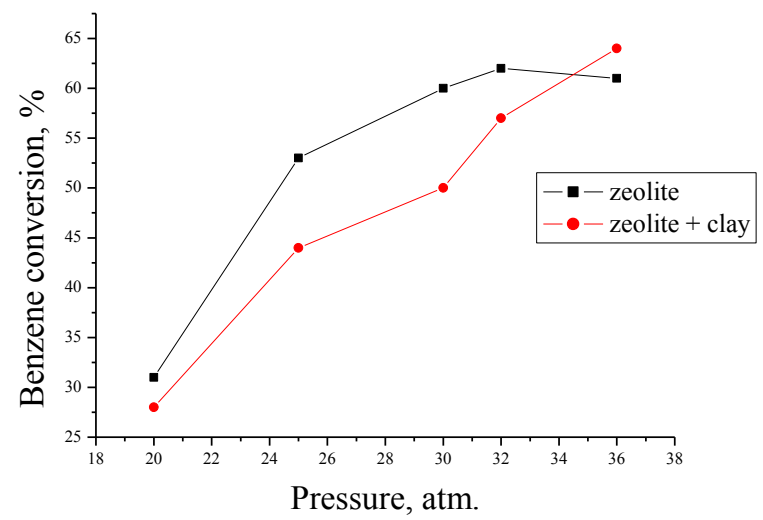

Fig. 4. The relationship between benzene conversion and under the $30 \mathrm{~atm}$. Pressure.

For these purposes we select clay, content in the catalyst varies from 10 to $30 \mathrm{wt} \%$. Mixing of sample clay reduces its acidity, but the specific surface increased. Particularly significant effect on the structure of zeolite provides clay $(10 \%)$ and also on the yield of desired products at higher temperatures and pressures. This means that the clay-containing zeolite structure during carbonization undergoing structural changes, and becomes resistant to coking processes. Further increase clay in catalyst reduces the mechanical strength under carbonization. Samples containing 20 and $30 \%$ of clay, characterized fragile structure. Therefore, the further addition of clay into the zeolite is not appropriate. Since the resulting granules quickly disintegrate.

Target product in benzene hydrogenation process is preferably cyclohexane. The resulting product can be used as a high-octane component of motor fuels, and as feedstock for petrochemical processes.

\section{CONCLUSION}

The results showed that the study of the catalytic activity of $\mathrm{Rh}$ catalysts were active and selective $1 \% \mathrm{Rh}$ zeolite catalyst. In the reaction mixture were desired the formation of the maximum amount of the targeted products. At higher temperatures, largely derived benzene alkylation, resulting in reduced yield of cyclohexane.

Carbonized apricot pits $0.5 \%$ Rh-promoted exhibits catalytic activity in hydrogenation of benzene in the temperature mode, but by increasing the space velocity rapidly loses activity.

Rh catalyst on calcined $\mathrm{Al}_{2} \mathrm{O}_{3}$ at $550{ }^{\circ} \mathrm{C}$ showed markedly less stability in the hydrogenation of benzene in comparison to the other samples.

$0.5 \%$ Rh- promoted clay-containing zeolite exhibits catalytic activity in the hydrogenation of benzene in the temperature range $280-350{ }^{\circ} \mathrm{C}$, and also has high selectivity to output cyclohexane and DMB.

As a result, turned improve the environmental performance of motor fuel to achieve the parameters corresponding to Euro-4 standards.

\section{REFERENCES}

[1] X.-Y. Quek, Y. Guan, and E. J. M. Hensen, "Structure sensitivity in the hydrogenation of unsaturated hydrocarbons over Rh nanoparticles," Catal. Today. vol. 183, pp. 72-78, 2012.

[2] O. N. Karatun, N. B. Kapizova, and A. Y. Morozov, "Dearomatisation way of the gasoline fraction," RF Patent No. 2501842, 2013.

[3] H. Sun, Y. Pan, Sh. Li, Y. Zhang et al., "Selective hydrogenation of benzene to cyclohexene over Ce-promoted Ru catalysts," Journal of Energy Chemistry, vol. 22, no. 5, pp. 710-716, 2013.

[4] J. B. Joo, P. Kim, W. Kim, Y. Kim, and J. Yi, "Effect of the preparation conditions of carbon-supported Pt catalyst on PEMFC performance," $J$. Appl. Electrochem. vol. 39, pp. 135-140, 2009.

[5] Zh. Liu, H. Sun, D. Wang et al., "Selective Hydrogenation of Benzene to cyclohexene over Ru-Zn catalyst with Nanosized Zirconia as Dispersant," Chin. J. Catal., vol. 31, pp. 150-152, 2010.

[6] A. Stanislaus, A. Marafi, and M. S. Rana, "Recent advances in the science and technology of ultra low sulfur diesel (ULSD) production," Catal. Today., vol. 153, pp. 1-68, 2010.

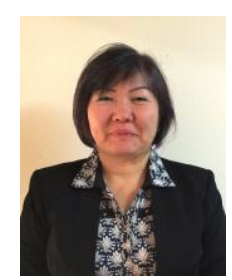

Tanirbergenova Sandugash has completed her $\mathrm{PhD}$ degree at the age of 39 from al-Farabi Kazakh National University, Department of Chemistry and Chemical Technology. She is a scientific secretary of Institute of Combustion Problems, and a senior researcher in Laboratory of Carbon Nanomaterial's. She has published more than 20 papers in reputed journals and 3 innovative patents RK. She is also the head of projects financed by the Committee of 


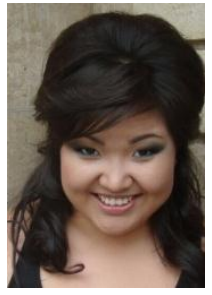

Temirkhan Aliya has completed her bachelor's degree at Russian University of Chemical Technologies of D.I.Mendeleev, Department of Organic Chemistry, specialty Organic and petro-chemical synthesis in 2011. And in 2014 she has completed her master's degree from al-Farabi Kazakh National University, Department of Chemistry and Chemical Technology. She is a junior researcher in Laboratory of Carbon Nanomaterial's, Institute of Combustion Problems. She has published more than 5 papers in reputed journals and 1 innovative patent RK.

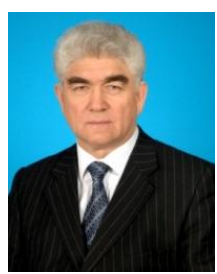

Mansurov Zulhair Aymuhametovich was born on June 26, 1946. He holds the doctor of chemistry degree, and he is a professor at al-Farabi Kazakh National University, Department of Chemistry and Chemical Technology. He is the CEO of Institute of Combustion Problems. He has published more than 50 papers in reputed journals and 30 innovative patents RK. He is Science of MES RK

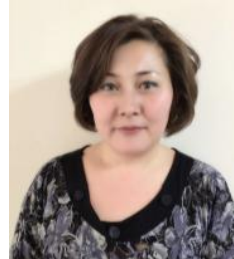

Zhylybayeva Nurzhamal Kydyrkhankyzy was born on February 18, 1978 at Province of Almaty. She received her PhD degree from the Department of Chemistry and Chemical Technology, al-Farab Kazakh National University, Almaty, Kazakhstan. She has been a lecture of chemical engineering in al-Farabi Kazakh National University during 3 years. She is a senior researcher in Laboratory of carbon nanomaterial's, Institute of Combustion Problems. She has published over 10 papers in reputed journals and 4 innovative patents RK.

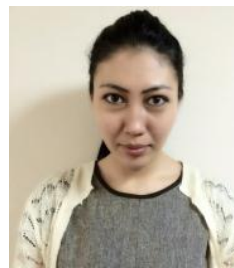

Naurzbayeva Gulmira Markhabayevna was born on May 20, 1987. She received her master's degree from the Department of Chemistry and Chemical Technology. She is a junior researcher in Laboratory of Carbon Nanomaterial's, Institute of Combustion Problems. She has published over 5 papers in reputed journals and 1 innovative patent RK. 
